\title{
Multiple abiotic and biotic drivers of soil water storage capacity in temperate forests recovering from disturbances
}

\section{Shufang Liu}

Chinese Academy of Sciences

\section{Zuoqiang Yuan}

Chinese Academy of Sciences

\section{Arshad Ali}

Nanjing Forestry University

\section{Anvar Sanaei}

Chinese Academy of Sciences

\section{Fan Ding}

Shenyang Agriculture University

\section{Di Zheng}

Chinese Academy of Sciences

\section{Shuai Fang}

Chinese Academy of Sciences

Zhaojie Jia

Nanjing Forestry University

Zhao Tao

Nanjing Forestry University

Fei Lin

Chinese Academy of Sciences

Ji Ye

Chinese Academy of Sciences

\section{Xugao Wang}

Chinese Academy of Sciences

Zhanqing Hao ( $\sim$ hzq@iae.ac.cn )

Northwestern Polytechnical University https://orcid.org/0000-0003-2875-6419

\section{Manuscript}

Keywords: biodiversity, ecosystem functions, functional trait composition, logging, niche complementarity, mass ratio 
Posted Date: February 18th, 2021

DOl: https://doi.org/10.21203/rs.3.rs-170425/v1

License: (c) (i) This work is licensed under a Creative Commons Attribution 4.0 International License. Read Full License 


\section{Abstract}

\section{Background and aims}

Soil water storage capacity acts as a vital forest function to intercept rainfall and retain water for plant growth processes. However, whether or how plant functional trait diversity and composition regulate soil water storage capacity remains poorly understood.

\section{Methods}

Structural equation modeling (SEM) was used to detect the direct and indirect effects of multiple biotic (i.e., functional trait composition and functional diversity) and abiotic (topography and soil organic carbon) factors on soil water storage capacity, i.e., in terms of soil capillary water storage content (CW), soil non-capillary water storage content (NCW), and soil saturated water storage content (TSW), in temperate forests recovering from different logging disturbance intensity levels.

\section{Results}

The community-weighted mean of specific leaf area $\left(\mathrm{CWM}_{\mathrm{SLA}}\right)$ increased $\mathrm{CW}$ but decreased NCW directly, whereas improved NCW and TSW indirectly via soil organic carbon. Disturbance influenced soil water storage capacity mainly in indirect ways via promoting $\mathrm{CWM}_{\mathrm{SLA}}$ and soil organic carbon. Elevation increased NCW and TSW but decreased CW directly, and it also had indirect effects on soil water storage capacity via decreasing $\mathrm{CWM}_{\mathrm{SLA}}$ and soil organic carbon. Moreover, soil organic carbon influenced NCW and TSW directly or mediated the effects of elevation, disturbance, and CWM $\mathrm{SLA}_{\text {A }}$ on soil water storage capacity.

\section{Conclusions}

The quick return on investments trait of $\mathrm{CWM}_{\mathrm{SLA}}$ shows a positive effect on soil water storage capacity (CW and TSW), supporting the mass ratio mechanism in temperate forests recovering from disturbances. Soil organic carbon also presents additional importance to soil water storage capacity.

\section{Introduction}

Soil water storage capacity is one of the major soil functions which could potentially affect biogeochemical cycle, and hence, mitigate the influences of global climate change (Lü et al. 2015; Reich et al. 2018; Zhang et al. 2016). For example, soil water storage capacity regulates the water flow to alleviate the negative effect of hydrological variations, which in turn could regulate climate change events (Andreassian 2004; Zhang et al. 2011). In addition, the plant diversity effect usually presented a 
significant relation with soil water-related functions, indicating that plant diversity is one of the main biotic factors underlying soil water storage capacity (Kammer et al. 2013; Wen et al. 2019). Although several studies have reported the differences of soil water storage capacity among diverse vegetation types (Fang et al. 2011; Hao and Wang 1998; Jiao et al. 2011; Wang et al. 2013), none of the studies has reported on the complex interactions of biotic (functional trait diversity and community-weighted mean trait composition; CWM) and abiotic (i.e., topography, climate, and edaphic) factors for determining soil water storage capacity in forests recovering from logging disturbances (see Fig. S1 for a conceptual model).

It is generally well explored that the niche complementarity (the diversity effect) and mass ratio (the CWM effect) mechanisms could explain several ecosystems functions in natural assembled communities (van der Plas 2019). For example, in the semi-arid grassland ecosystem of China, plant diversity is positively correlated with soil water content with the increasing community coverage (Wu et al. 2014). In addition, higher species diversity could improve soil water infiltration capacity by changing soil properties as the long-term feed-back between soil and high above- and below-ground biomass (Liu et al. 2019). Indeed, the ecological mechanism behind this positive effect might be associated with the niche complementarity hypothesis i.e., species having different niches can use the available resources or facilitate their coexistence, then could improve ecosystem functions (Lange et al. 2019; Tilman et al. 1997). Besides the diversity effect, the trait of most dominant species (i.e. measured in CWM) could also drive ecosystem functions under the assumption of the mass ratio hypothesis (Grime 1998). For instance, the CWM of specific leaf area $\left(\mathrm{CWM}_{\mathrm{SLA}}\right)$ could explain more variance of water retention capacity than other predictors in semi-arid forest ecosystems (Teixeira et al. 2020). Moreover, tree species functional group, litterfall quality per se, and its decomposing rate rather than the diverse or the amount of litterfall input better explained the variance of soil functions (Dawud et al. 2017). Taken together, these prominent ecological theories could provide the quantitative relationships between diverse plant species, composition and soil water storage capacity, and hence may improve our understanding regarding underlying mechanisms when simultaneously testing their effects on ecosystem functions (Fig. S1) (Ali et al. 2017; Becknell and Powers 2014; Yuan et al. 2019).

Many advanced ecological studies have suggested that abiotic factors (e.g., topography) can potentially affect plant diversity, composition and ecosystem functions (Jucker et al. 2018). For example, changes in soil physicochemical properties could be highly attributed to topographical factors (Chapin et al. 2011; Zhang et al. 2019). Fine soil particles, as well as soil organic carbon, tended to accumulate in lower elevational gradients because of the soil erosion processes when rainfall events appeared (Chapin et al. 2011; Zhang et al. 2019). Accordingly, soil water retention ability could be enhanced by fine soil texture, whereas soil water infiltration function could be improved by increased soil organic carbon contents (Chen et al. 2019; Fischer et al. 2015; Zhang et al. 2019). On the other hand, elevation as an important topographical factor can regulate soil water storage capacity indirectly through influencing climatic factors which in turn could impact vegetation structure and composition (Hao et al. 2003). For example, along with the decline of elevational gradients, plant composition presents to be a quick return on 
investment species, and this kind of litterfall could be beneficial for the accumulation of soil organic carbon which in turn could influence the soil structure and water storage capacity (Cotrufo et al. 2013; Fischer et al. 2019).

Under global change circumstances, forest ecosystems are impacted by a diversity of human activities, i.e., logging disturbance which is a common disturbance for timber use in forests (Edwards et al. 2014), resulting in changing vegetation structure and functions. The disturbance activities in forests could lead to alteration of forest types, associated above- and below-ground functions (Millar and Stephenson 2015; Yuan et al. 2018) as well as impact biogeochemical processes (de Avila et al. 2018). As such, the time lag effect of soil water storage functions may appear because of the different recovering rate of ecosystem functions and the process of plant-soil feedback (Thom and Seidl 2016; Trumbore et al. 2015). For instance, a decade-long Jena Experiment proved that plant species diversity affecting soil water contents from the shading effect in the early years was shifted to the soil properties in later years (Fischer et al. 2019). Although the effects of different types of disturbance (e.g., logging, fire, cutting, clearing) on different forest functions have been widely reported (Edwards et al. 2014), there is no actual study dealing with soil water storage capacity in the forests recovering from logging disturbances. This knowledge is crucial for understanding forests resilience and recovering from disturbances as increasingly considered vital in the face of climate change and human interventions (Seidl et al. 2016).

This study aims to explore how multiple biotic (i.e., functional trait composition and functional diversity) and abiotic (topography and soil organic carbon) factors drive soil water storage capacity, i.e., in terms of capillary water storage content (CW), soil non-capillary water storage content (NCW), and soil saturated water storage content (TSW), in temperate forests recovering from different logging disturbance intensity levels (Fig. 1). To do so, we used data from eleven permanent forest sites (in total 260 subplots) on Changbai Mountain in the northeast of China where forests underwent through three disturbance intensity levels. Using the conceptual model (Fig. 1), we answered the following main research questions. 1) Which ecological mechanism - the mass ratio or the niche complementarity - explain variation in soil water storage capacity? 2) How do disturbance and topographic factors affect soil water storage capacity directly, and indirectly via functional trait diversity, CWM of trait, and soil organic carbon. 3) How does soil organic carbon mediate the effects of disturbance, elevation, functional trait diversity, and CWM of trait on soil water storage capacity? We hypothesize that multiple abiotic and biotic factors jointly regulate soil water storage capacity in temperate forests recovering from logging disturbances.

\section{Materials And Methods}

\subsection{Study area, sites and forests}

Our study area is located in the northeast of China, covering the Liaoning and Jilin Provinces (Fig. 1), which is classified as a temperate continental climate. The mean annual air temperate is $2.8^{\circ} \mathrm{C}$, and the coldest and warmest monthly mean are $-13.7^{\circ} \mathrm{C}$ in January and $19.7^{\circ} \mathrm{C}$ in July (Hao et al. 2007). The mean annual participation is $700 \mathrm{~mm}$ which mostly occurs during the growing seasons (from June to 
September). Broad-leaved Korean pine ( $P$. koraiensis) mixed forest, well-known for their high species diversity, productivity and complex stand structure, was the dominant vegetation type in the study region. The predominant soil type of the studied area is Eutric cambisols according to the FAO soil classification system (Hao et al. 2007). Some areas had been subjected to variable intensities of human disturbances, but there were no severe human disturbances since 1998 when the forest protection policy was strictly implemented (Dai et al. 2004). Thus, forests recovering from disturbances include stands with different successional stages in the study area (Chen et al. 2014).

To quantify the effects of abiotic factors, disturbance intensity, plant trait diversity and composition on soil water storage capacity, we established 11 permanent forest sites during 2012 2013 (Table 1), and then re-investigated those forest plots at an interval of five years using the standard field approaches (Yuan et al. 2018). Within each site, all trees with a diameter at breast height (DBH) $>1 \mathrm{~cm}$ were marked, measured, recognized to species level, and positioned in contiguous $20 \times 20$ subplots (Hao et al. 2007). In this way, our data covered 22,766 stems in total belonging to 81 species, 46 genera, and 26 families across 260 subplots (Yuan et al. 2018). In addition, the topography of each subplot was measured by assessing the elevation of four corners of each subplot using Electronic Distance Measuring Device (Hao et al. 2007), and then the mean elevation, convexity and slope were calculated for each subplot (Harms et al. 2001). Elevation of the studied plots ranged from 640.4 to $1023.1 \mathrm{~m}$.

Table 1. The descriptive summary of the studied sites and plots. 


\begin{tabular}{|c|c|c|c|c|c|c|c|c|}
\hline Site & $\begin{array}{l}\text { Site size (ha) } \\
\text { (dimension, m) }\end{array}$ & $\begin{array}{l}\text { No. of } \\
\text { subplots }\end{array}$ & \multirow[t]{2}{*}{$\begin{array}{l}\text { Latitude } \\
\text { longitude }\end{array}$} & \multicolumn{2}{|c|}{ Elevation $(\mathrm{m})^{\mathrm{a}}$} & \multicolumn{2}{|c|}{ Species richness } & $\begin{array}{l}\text { DBH } \\
(\mathrm{cm})^{\mathrm{a}}\end{array}$ \\
\hline \multicolumn{8}{|c|}{ Plots of low-disturbance level } & \\
\hline L1 & $1(100 * 100)$ & 25 & $\begin{array}{l}127.98 \mathrm{~N} \\
42.35 \mathrm{E}\end{array}$ & $\begin{array}{l}877.5 \\
(875.1\end{array}$ & 9.7) & 25 & & $\begin{array}{l}8.68 \\
(1.0, \\
115.2)\end{array}$ \\
\hline L2 & $1(100 * 100)$ & 25 & $\begin{array}{l}126.23 N ; 43.18 \\
\text { E }\end{array}$ & $\begin{array}{l}727.5 \\
(724.2\end{array}$ & $1.1)$ & 35 & & $\begin{array}{l}8.98 \\
(1.0,152)\end{array}$ \\
\hline L3 & $1(100 * 100)$ & 25 & $\begin{array}{l}127.88 \mathrm{~N} \\
42.25 \mathrm{E}\end{array}$ & $\begin{array}{l}998.8 \\
(995.6\end{array}$ & 02.1) & 38 & & $\begin{array}{l}7.56 \\
(1.0,110.0)\end{array}$ \\
\hline L4 & $1(100 * 100)$ & 25 & $\begin{array}{l}127.91 \mathrm{~N} \\
42.21 \mathrm{E}\end{array}$ & $\begin{array}{l}1107.2 \\
(1105 .\end{array}$ & 108.3) & 21 & & $\begin{array}{l}8.64 \\
(1.0,96)\end{array}$ \\
\hline \multicolumn{9}{|c|}{ Plots of medium-disturbance level } \\
\hline M1 & $1(100 * 100)$ & 25 & $127.86 \mathrm{~N}$ & $42.48 \mathrm{E}$ & $\begin{array}{l}1010.9 \\
(1016 .\end{array}$ & 1023.1) & 34 & $\begin{array}{l}7.83 \\
(1.0,96.5)\end{array}$ \\
\hline M2 & $1(100 * 100)$ & 25 & $127.94 \mathrm{~N}$ & $44.01 \mathrm{E}$ & $\begin{array}{l}721.6 \\
(698.4\end{array}$ & 3.7) & 41 & $\begin{array}{l}8.98 \\
(1.0,75.0)\end{array}$ \\
\hline M3 & $0.8(80 * 100)$ & 20 & $124.79 \mathrm{~N}$ & $40.91 \mathrm{E}$ & $\begin{array}{l}834.1 \\
(817.0\end{array}$ & $51.0)$ & 40 & $\begin{array}{l}7.22 \\
(1.0,60.9)\end{array}$ \\
\hline \multicolumn{9}{|c|}{ Plots of high-disturbance level } \\
\hline $\mathrm{H} 1$ & $1(100 * 100)$ & 25 & $126.48 \mathrm{~N}$ & 42.36E & $\begin{array}{l}758.6 \\
(749.6\end{array}$ & $64.8)$ & 47 & $\begin{array}{l}3.4 \\
(1.0,75.0)\end{array}$ \\
\hline H2 & $1(100 * 100)$ & 25 & $128.17 \mathrm{~N}$ & $42.19 \mathrm{E}$ & $\begin{array}{l}652.9 \\
(640.4\end{array}$ & $66.2)$ & 45 & $\begin{array}{l}6.35 \\
(1.0,68.5)\end{array}$ \\
\hline H3 & $1(100 * 100)$ & 25 & $130.16 \mathrm{~N}$ & $43.39 \mathrm{E}$ & $\begin{array}{l}717.7 \\
(705.6\end{array}$ & 26.2) & 34 & $\begin{array}{l}6.3 \\
(1.0,70.0)\end{array}$ \\
\hline H4 & $0.6(60 * 100)$ & 15 & $124.90 \mathrm{~N}$ & 41.33E & $\begin{array}{l}892.2 \\
(873.1 \\
\end{array}$ & 09.4) & 43 & $\begin{array}{l}7.15 \\
(1.0,53.8) \\
\end{array}$ \\
\hline
\end{tabular}

a Mean value and range (min, max) of each $20 * 20 \mathrm{~m}$ subplots. $\mathrm{DBH}$, diameter at breast height.

\subsection{Assessment of disturbance intensities}

The 11 permanent sites are located in Broad-leaved Korean pine mixed forest fragments which underwent three levels of logging disturbance, and the sites provide a good platform for the research of biodiversity and ecosystem functions under disturbance (Dai et al. 2004; Song et al. 2014; Yuan et al. 2018). The disturbance intensity of each plot was assessed by counting the number of removed tree stumps, and the disturbance was mostly happened in1990s (Kahl and Bauhus 2014). Besides, the official records of the Local Forestry Bureau in Jilin and Liaoning Provinces were checked to collect the relevant selective logging data. Collectively, plots were primarily classified into three disturbance intensity levels according to the partial harvesting (e.g., thinning, selective harvesting): relatively low (<10\%), medium (10-20\%), and high $(20 \sim 30 \%)$ disturbance. Plots with medium and high disturbance levels were primarily located around the residential area, whereas plots with low disturbance level were located in the main region of 
the Changbai Mountain Nature Reserve (Fig. 1), which was established in 1960 and is part of the World Biosphere Reserve Network under the Man and the Biosphere Project in 1980 (Shao et al. 1994).

\subsection{Quantification of plant functional trait diversity and composition indices}

For quantifying the multiple facets of plant diversity, six functional traits were measured which were closely associated with forest growth, recruitment and death (Yuan et al. 2019), including maximum height (MH), leaf area (LA), specific leaf area (SLA), leaf carbon content (LCC), leaf nitrogen content (LNC), and leaf phosphorus content (LPC). The detailed measurement approaches for these six functional traits are described in Yuan et al. (2016). Using the data of six functional traits, we measured three multidimensional functional trait diversity indices, namely, functional richness (FRic), functional evenness (FEve), and functional dispersion (FDis). FRic represents the multivariate traits space that species in the community occupied, FEve indicates the regularity of community traits distribution, and FDis is the mean distance of the species trait to the centroid of all species weighted by basal area (Laliberté and Legendre 2010; Villeger et al. 2008). Besides, we also calculated the community-weighted mean of each trait $\left(\mathrm{CWM}_{\mathrm{MH}}, \mathrm{CWM}_{\mathrm{LNC}}, \mathrm{CWM}_{\mathrm{LCC}}, \mathrm{CWM}_{\mathrm{LPC}}, \mathrm{CWM}_{\mathrm{LA}}\right.$, and CWM $\left.\mathrm{SLA}\right)$ within each plot, weighted by the species' relative basal area, to represent the plant functional trait composition (Ali et al. 2017; Yuan et al. 2019). The CWM and FD indices were calculated by FD package in R 3.5.3 (Laliberté and Legendre 2010).

\subsection{Quantification of soil water storage capacity and soil organic carbon}

In 2018, we randomly selected three soil sampling sites in the midpoints between the central point and four corners in each $20 \mathrm{~m} \times 20 \mathrm{~m}$ subplot. In each sampling site, two soil corers using stainless cylinders of $100 \mathrm{~cm}^{3}$ in volume were selected for the bulk soil density and capillary water storage contents measurement after removing large debris. The corers containing large roots were abandoned for the precise analyses of data. Subsequently, five soil cores (3.8 cm in diameter, $10 \mathrm{~cm}$ deep) at each sampling point were collected, pooled, and transferred to the laboratory with plastic zipper bags for further chemical analyses. Each soil sample was further divided into two parts, i.e., one for soil organic carbon analysis using the dichromate oxidation method (Lu 1999), and another one for soil moisture measurement after $12 \mathrm{hr}$ dried at $105^{\circ} \mathrm{C}$.

Soil water storage capacity was measured through soil porosity, and this could be divided into capillary porosity, non-capillary porosity and total porosity corresponding to soil capillary storage (CW), soil noncapillary storage (NCW), and soil saturated water storage (TSW) (Chen et al. 2019; Xia et al. 2017). The $\mathrm{CW}$ represents the soil water content in the soil water retention curve when the pressure is $-33 \mathrm{kPa}$ whereas the NCW reflects the water contents difference between $0 \sim-33 \mathrm{kPa}$ (Ahuja et al. 1993; Liu et al. 2009). Moreover, these two parts also indicate soil water retention and infiltration capacity (Mo et al. 2011; Rabot et al. 2018). TSW, CW, and NCW were calculated using Eq. (1), Eq. (2) and Eq. (3) (Chen et al. 2019; Wu et al. 2016; Zhang et al. 2010): 


\section{$C W=10000 \times C P \times h$}

\section{$N C W=10000 \times N C P \times \hbar$}

Where TP is the total soil porosity (\%) measured as TP $=(1-\mathrm{BD} / \mathrm{ds}) \times 100, \mathrm{BD}$ is the soil bulk density (g $\left.\mathrm{cm}^{3}\right)$, ds is the soil particle density $\left(2.65 \mathrm{~g} \mathrm{~cm}^{-3}\right)$; $\mathrm{CP}$ is the soil capillary porosity (\%) measured as $\mathrm{CP}=$ $\left(W_{C} / V\right) \times 100, W c$ is the soil capillary water contents $\left(\mathrm{g} \mathrm{cm}^{3}\right)$ (Liu et al. 2009), $\mathrm{V}$ is the volume of the soil core $\left(\mathrm{cm}^{3}\right)$; NCP is the soil non-capillary porosity (\%) measured as NCP $=(T P-C P) \times 100 ; \mathrm{h}$ is the height of soil top layer $(0.2 \mathrm{~m}), \mathrm{TSW}$ is the total soil water storage content $\left(\mathrm{t} \mathrm{hm}^{-2}\right), \mathrm{NCW}$ is the non-capillary storage content $\left(\mathrm{t} \mathrm{hm}^{-2}\right)$, and $\mathrm{CW}$ is the capillary storage content $\left(\mathrm{t} \mathrm{hm}^{-2}\right)$.

Total soil porosity (TP) was measured based on the measured soil bulk density while assuming that soil particle density is $2.65 \mathrm{~g} \mathrm{~cm}^{-3}, \mathrm{~W}_{\mathrm{C}}$ was additional water weight after placing the stainless cylinders soil core in a tray with a 5-mm level of water until filter paper at the top of each core became moist (Liu et al. 2009), whereas non-capillary was the difference between TP and CP (Eq. (3)) (Wu et al. 2016).

\subsection{Statistical analyses}

We assessed the effects of disturbance on soil water storage capacity (i.e. TSW, NCW and CW) using a two-way ANOVA with Tukey's test as a post hoc analysis to assess the significant differences among disturbance levels. As such, we also tested the differences for associated variables, which may influence soil water storage capacity (i.e. above-ground and below-ground variables), among disturbance intensity levels.

Before testing the conceptual model in Fig. S1, we assessed the spatial autocorrelation in the response variables (TSW, NCW and CW) among subplots using the generalized least-square models (GLS) with and without spherical autocorrelation. Our GLS analysis indicated that the models without spherical autocorrelation structures usually showed the lower Akaike Information Criterion (AIC) values compared to spherical autocorrelation models (Table S2, S3 and S4), suggesting that there was no strong spatial autocorrelation among subplots.

Based on Pearson's correlation (Table S5), the best combination of variables (Tables S6 and S7), and the conceptual model (Fig. S1), we identified elevation, CWM of traits, functional trait diversity, and soil organic carbon as the best factors influencing soil water storage capacity (i.e. CW, NCW, and TSW). To test the conceptual model in Fig. S1, we used structural equation modeling (SEM) because it allows us to test the multiple theories, direct and indirect effects. To critically evaluate the best-fitted SEM (Hoyle 2012), we used the highest Bentler's Comparative Fit Index (CFI > 0.90), the root mean square error of 
approximation (RMSEA $\leq 0.05)$, chi-square $\left(X^{2}\right)$ test $(P$-value $>0.05)$, standardized root mean square residual $(S R M R \leq 0.05)$ and lowest AIC value. To compare the mass ratio hypothesis and niche complementarity effects on soil water storage capacity, we selected CWM $\mathrm{SLA}_{\mathrm{A}}$ and FEve as the representative of plant functional trait composition and diversity, respectively, in SEMs. The direct, indirect, and total effects of predictors on response variables were calculated. The relative importance of each predictor was calculated as the percent of the given predictor standardized coefficient to the sum of standardized coefficients of all predictors (Yuan et al. 2019).

To complement the results from SEMs, we also conducted partial regressions and simple bivariate regressions (Grace et al. 2016). The SEM analysis was conducted using the "lavaan" package (Rosseel 2012). All analyses were conducted in R. 4.0.2 (Team RDC, 2019). All predictors in our research were standardized to a mean of 0 and standard deviation of 1 , and the response factors (i.e. CW, NCW and TSW) were natural-log transformed before further analyses. Summary of variables used in the analysis is provided in Table S1.

\section{Results}

\subsection{ANOVA: differences for soil water storage capacity and associated variables among disturbance intensity levels}

The ANOVA results showed that CW and TSW significantly increased with increasing disturbance intensity, but no significant differences were found for NCW (Fig. 2). The average values for CW, NCW, and TSW of the top $20 \mathrm{~cm}$ soil layer were respectively $1118.2 \mathrm{t} \mathrm{hm}^{-2}, 468.2 \mathrm{t} \mathrm{hm}^{-2}$, and $1604.7 \mathrm{t} \mathrm{hm}^{-2}$ while showing general variations across eleven forest plots and disturbance intensity levels (Fig. S2). Meanwhile, above-ground biomass and soil bulk density decreased whereas plant species diversity indices and soil organic carbon increased with increasing disturbance intensity levels (Fig. S3). Furthermore, disturbance also severely influenced most of the community trait composition; for example, $\mathrm{CWM}_{L \mathrm{~A}}, \mathrm{CWM}_{\mathrm{SLA}}, \mathrm{CWM}_{\mathrm{LNC}}$, and $\mathrm{CWM}_{\mathrm{LPC}}$ increased whereas $\mathrm{CWM}_{\mathrm{MH}}$ and $\mathrm{CWM}_{\mathrm{LCC}}$ decreased with increasing disturbance intensity levels (Fig. S3).

\subsection{SEMs: what determines soil water storage capacity}

The tested best-fitted SEMs showed that FEev did not significantly influence soil water storage capacity (i.e. $\mathrm{CW}, \mathrm{NCW}$, and TSW) whereas $\mathrm{CWM}_{\mathrm{SLA}}$ influenced them either directly and/ or indirectly via soil organic carbon (Fig. 3; Tables S8, S9 and S10). More specifically, CWM SLA had significantly increased CW but decreased NCW directly. However, $\mathrm{CWM}_{\mathrm{SLA}}$ improved NCW and TSW indirectly via soil organic carbon (Fig. 3; Tables S8 and S9). Although disturbance did not influence soil water storage capacity directly, it had indirect variable (positive or negative) effects on soil water storage capacity via promoting $\mathrm{CWM}_{\mathrm{SLA}}$ and soil organic carbon, respectively (Fig. 3; Tables S8, S9 and S10). Likewise, elevation showed indirect effects on soil water storage capacity via decreasing $\mathrm{CWM}_{\mathrm{SLA}}$ and soil organic carbon, but it directly increased NCW and TSW, and decreased CW (Fig. 3; Tables S8, S9 and S10). In SEMs, soil organic carbon 
demonstrated the significant importance of mediating the effects of elevation, disturbance and $\mathrm{CWM}_{\mathrm{SLA}}$ on soil water storage capacity, as it had crucial improvement influence on NCW and TSW directly(Fig. 3; Tables S8, S9 and S10).

The relative contribution analysis (Fig. 4a) showed that elevation was the most important influencing factor for CW but not for TSW, whereas elevation, soil organic carbon and disturbance contributed much to the explained variation in NCW. Disturbance and soil organic carbon seemed to be the most important

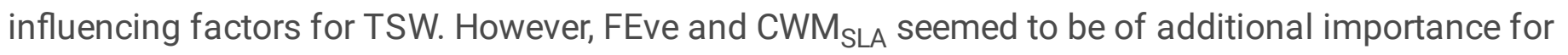
explaining variation in CW, NCW and TSW, and were almost equally important across CW, NCW and TSW (Fig. 4a). In addition, the comparison of direct and indirect effects showed that the direct effects of disturbance, elevation, soil organic carbon, FEve and CWM $\mathrm{SLA}_{\mathrm{S}}$ were much higher than indirect effects on CW (Fig. 4b). However, the indirect effects of disturbance mattered for explaining variation in NCW, whereas the indirect effects of disturbance, elevation, $\mathrm{CWM}_{\mathrm{SLA}}$ and FEve mattered much for explaining variation in TSW (Fig. 4b).

\subsection{Supporting analyses: partial regressions and simple bivariate regressions}

The SEMs results showed that soil organic carbon was the important variable which influenced soil water

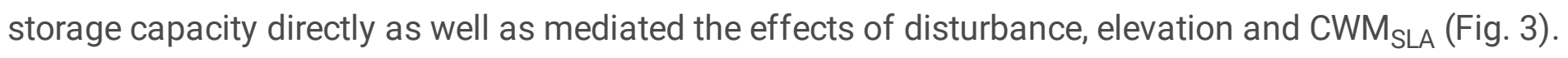
We, therefore, further conducted the simple regression and partial regression analyses between soil organic carbon and soil water storage capacity (Fig. S4) to clarify the importance of soil organic carbon to soil water storage capacity. The partial regression analysis showed that soil organic carbon was significantly positively related with NCW and TSW but not related with CW when other factors (disturbance, elevation, $\mathrm{CWM}_{\mathrm{SLA}}$, and $\mathrm{FE}_{\mathrm{VE}}$ ) were kept constant (Fig. S4a). This was a contrast with the simple regression analysis (Fig. S4b), which showed that soil organic carbon was significantly related with $\mathrm{CW}$ but not related with NCW, whereas soil organic carbon showed a significant constant relationship with TSW in both simple and partial regression analyses (Fig. S4). The partial regression results were in line with SEMs results, indicated that soil organic carbon was controlled by elevation,

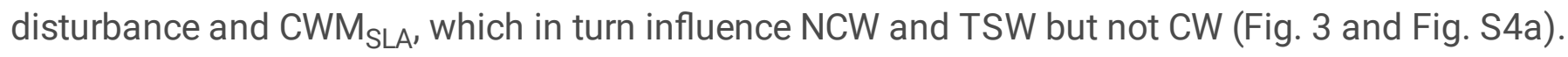

All bivariate relationships for hypothesized paths in SEMs are provided in Fig S4, S5 and S6. More specifically, we found that there was a significant positive bivariate relationship between CWM traits and soil water storage capacity (Figs S5, S6 and S7). Typically, high $\mathrm{CWM}_{\mathrm{LA}}, \mathrm{CWM}_{\mathrm{SLA}}, \mathrm{CWM}_{\mathrm{LNC}}$, and $C \mathrm{WM}_{\mathrm{LPC}}$ values but low $\mathrm{CWM}_{\mathrm{LCC}}$ and $\mathrm{CWM}_{\mathrm{MH}}$ values were beneficial for $\mathrm{CW}$ and TSW, whereas we found the opposite results for NCW. However, there was no consistent and robust relationship between diversity indices and soil water storage capacity (Figs S5, S6 and S7).

\section{Discussion}


In this study, we tease apart the direct and indirect effects of abiotic (elevation and soil organic carbon) and biotic (functional trait diversity and composition) on soil water storage capacity in temperate forests recovering from logging disturbances. Our results can be discussed in the following points: 1) CWM of a trait (functional composition) was a much more important direct factor to soil water storage capacity than functional trait diversity as well as providing an important role for mediating the effects of elevation and disturbances on soil water storage capacity; 2) disturbance influenced soil water storage capacity indirectly via soil organic carbon and CWM of trait but not directly; 3 ) soil organic carbon was also the key factor influencing soil water storage capacity directly as well provided an important role for mediating the effects of elevation, disturbances and CWM of trait on soil water storage capacity; and 4) elevation regulated soil water storage capacity directly and indirectly via soil organic carbon and CWM of a trait.

First, we found that plant community trait composition rather than functional trait diversity was the key factor influencing soil water storage capacity (Finegan et al. 2015; Loreau and Hector 2001; Xu et al. 2020). Our finding was in contrary with the importance of functional trait diversity on hydrological ecosystem service and soil water content (Fischer et al. 2015; Wen et al. 2021), but was consistent with other ecosystem functions, such as aboveground and soil carbon stocks, fine root biomass and necromass (Lin et al. 2016; Xu et al. 2020). This result confirms the mass ratio effect instead of the niche complementarity effect for the explaining variation in soil water storage capacity in temperate forests. More specifically, we found that quick return on investment traits (i.e. high $\mathrm{CWM}_{\mathrm{LA}}, \mathrm{CWM}_{\mathrm{SLA}}, \mathrm{CWM}_{\mathrm{LNC}}$, and $\mathrm{CWM}_{\mathrm{LPC}}$ values; but low $\mathrm{CWM}_{\mathrm{LCC}}$ and $\mathrm{CWM}_{\mathrm{MH}}$ ) directly increased $\mathrm{CW}$, and slow return on investment traits improved NCW (Fig. 3, S5, and S6). This result might be due to the reason that quick return on investment leaf traits is usually linked with fast decomposing litterfalls, which could be beneficial to the formation of mineral-stabilized soil organic carbon (Cotrufo et al. 2013; Zhou et al. 2019) and soil macroaggregates (Blanco-Canqui and Lal 2007; Wang and Wang 2005), which in turn related to fine soil textures, thereby increasing $\mathrm{CW}$. Slow return on investment leaf traits has usually more recalcitrant litterfalls which may facilitate the formation of coarse particulate organic matter (Cotrufo et al. 2015) and large soil porosities while improving NCW as well as soil infiltration capacity (Liu et al. 2019). We found that that $\mathrm{CWM}_{\mathrm{SLA}}$ also improved NCW and TSW indirectly via increasing soil organic carbon, which was consistent with the notion that vegetation improves soil organic carbon contents, thereby enhancing soil water contents (Fischer et al. 2019; Liu et al. 2019). However, the total effect of CWM $\mathrm{M}_{\text {SLA }}$ on NCW was negative which was dominated by the direct pathway.

Second, we observed that logging disturbance significantly changed community trait composition (Fig. S3), and then changed soil water storage capacity in studied forests (Fig. 3). With the intensity of disturbance level, community weighted traits tended to be higher $C W M_{L A}, C W M_{S L A}, C W M_{L N C}$ and $C W M_{L P C}$ values but lower $\mathrm{CWM}_{\mathrm{LCC}}$ and $\mathrm{CWM}_{\mathrm{MH}}$ values (i.e. indicating the quick return on investment traits). This phenomenon followed the fact that past logging activities have decreased the number of large trees which in turn creating a forest gap, and hence, more light-demanding species are doing well in less disturbed forests (Yuan et al. 2018). Along with the transformation of the plant community, soil organic carbon content increased because of the large amount of easily decomposed litterfalls (Cotrufo et al.

Page $12 / 22$ 
2013). As such, disturbance mainly affected soil water storage capacity indirectly via CWM $\mathrm{CWA}_{\mathrm{S} A}$ and soil organic carbon, whereas there was no significant direct influence of disturbance on soil water storage capacity. The lack of direct effect of disturbance on soil water storage capacity might be due to the reason that the response of changes in soil properties to disturbances are usually slower than aboveground attributes following the plant-feedback processes (Trumbore et al. 2015). Hence, our study suggests that soil water storage capacity reacted slowly to disturbances, and careful consideration is required when studying or quantifying the consequences of disturbances on diverse ecosystem functions.

Third, we argue that soil organic carbon is the key factor of soil water characteristics responding to the plant transformation after disturbance. For example, soil organic carbon was an important response factor to the species richness which could change the soil water infiltration capacity in semiarid grasslands (Liu et al. 2019). In a recovering grassland, the soil water contents changed as a result of the accumulation of soil organic carbon as well as the improved soil aggregation (Fischer et al. 2019). In an alpine grassland, SOC dominated the soil water retention capacity in five different matric potentials (from 0 to $-1500 \mathrm{kPa}$ ) because of the large amount of SOC accumulated in the soil (Yang et al. 2014), and as such Rawls et al. (2003) reported that soil organic carbon has different effects on soil water retention capacity due to the change of soil textures. Our results demonstrated that soil organic carbon was as an important regulating factor for soil water storage capacity as disturbance happened, and hence, it controlled TSW in temperate forests. However, the influence of soil organic carbon on NCW and CW declined, which may be related to soil texture because of the great influence of elevation on CW and NCW (Liu et al. 2009; Wösten et al. 2001; Zhang et al. 2019).

Fourth, elevation showed significant influences on CWM of trait and soil organic carbon, as well as the important significant direct effect on soil water storage capacity. This result can be explained based on two main reasons. One reason could be linked with the changing in CWM of trait along the elevation which in turn changed in soil water storage capacity (Hao et al. 2007). Another reason could be due to the different soil erosion levels along elevation when rainfall happened, and hence fine soil components (i.e. higher clay and soil organic carbon contents) accumulated in low elevation areas (Chapin et al. 2011; Zhang et al. 2019). Moreover, the influences of elevation on soil texture could explain the significant differences in the relation of soil organic carbon with $\mathrm{CW}$ and NCW when bivariate and partial-regression analyses were conducted (Fig. S4). Elevation influenced soil fine particles and soil organic carbon together which confused the relationship between soil organic carbon and soil water storage capacity in bivariate analyses. However, SEMs disentangled these relations and presented us with the underlying possible reasons. So, this result highlights the necessity of an integral understanding of biotic and abiotic attributes influencing ecosystem functions (Grace et al. 2016).

\section{Conclusions}

Logging disturbances and elevation modulate the effects of CWM of traits on soil water storage capacity, and the quick return on investments of CWM of specific leaf area shows a positive effect on soil water 
storage capacity (CW and TSW). Hence, CWM of specific leaf area is a key biotic predictor for explaining variation in soil water storage capacity compared to functional trait diversity, supporting the mass ratio mechanism in temperate forests recovering from disturbances. As such, soil organic carbon was of additional importance to soil water storage capacity by affecting it directly or providing mediator role to link the responses of soil water storage capacity to elevation, disturbances, and CWM of specific leaf area. We argue that testing the effects of multiple abiotic and biotic factors on soil water storage capacity could advance our understandings into the influential ecological mechanisms underlying soil water storage capacity in forests under the context of human influences.

\section{Declarations}

\section{Acknowledgements}

This study was supported by the National Natural Science Foundation of China (31730015, 31961133027 and 41671050), Youth Innovation Promotion Association CAS (2017241), and the Key Laboratory of Geographical Processes and Ecological Security of Changbai Mountains, Ministry of Education (GPES202001). A. Ali is supported by the Special Project for Introducing Foreign Talents Jiangsu "Foreign Expert Hundred People Program" (Grant No. BX2019084), and the Metasequoia Faculty Research Startup Funding at Nanjing Forestry University (Grant No. 163010230).

\section{Authors' contributions}

Shufang Liu, Zuoqiang Yuan, and Zhanqing Hao conceived the ideas and designed methodology; Fang Ding, Di Zheng, Shuai Fang, Zhaojie Jia, Zhao Tao, Fei Lin, Ji Ye collected the data; Shufang Liu analysed the data; Shufang Liu led the writing of the manuscript. Zuoqiang Yuan, Arshad Ali, Anvar Sanaei, Xugao Wang contributed critically to the drafts and gave final approval for publication.

\section{Conflict of interest}

The authors declare no conflicts of interest.

\section{References}

1. Ahuja LR, Wendroth O, Nielsen DR (1993) Relationship between Initial Drainage of Surface Soil and Average Profile Saturated Conductivity Soil Science Society. of America Journal 57:19-25. doi:10.2136/sssaj1993.03615995005700010005x

2. Ali A, Yan E-R, Chang SX, Cheng J-Y, Liu X-Y (2017) Community-weighted mean of leaf traits and divergence of wood traits predict aboveground biomass in secondary subtropical forests. Sci Total Environ 574:654-662. doi:10.1016/j.scitotenv.2016.09.022 
3. Andreassian V (2004) Waters and forests: from historical controversy to scientific debate. J Hydrol 291:1-27. doi:10.1016/j.jhydrol.2003.12.015

4. Becknell JM, Powers JS (2014) Stand age and soils as drivers of plant functional traits and aboveground biomass in secondary tropical dry forest Canadian. Journal of Forest Research 44:604-613. doi:10.1139/cjfr-2013-0331

5. Blanco-Canqui H, Lal R (2007) Soil structure and organic carbon relationships following 10 years of wheat straw management in no-till. Soil Tillage Research 95:240-254. doi:10.1016/j.still.2007.01.004

6. Chapin FS, Matson PA, Mooney HA (2011) Principles of Terrestrial Ecosystem Ecology. Springer

7. Chen L, Wang L, Baiketuerhan Y, Zhang C, Zhao X, von Gadow K (2014) Seed dispersal and seedling recruitment of trees at different successional stages in a temperate forest in northeastern China. Journal of Plant Ecology 7:337-346. doi:10.1093/jpe/rtt024

8. Chen YP, Xia JB, Zhao XM, Zhuge YP (2019) Soil moisture ecological characteristics of typical shrub and grass vegetation on Shell Island in the Yellow River Delta. China Geoderma 348:45-53. doi:10.1016/j.geoderma.2019.04.011

9. Cotrufo MF, Soong JL, Horton AJ, Campbell EE, Haddix ML, Wall DH, Parton AJ (2015) Formation of soil organic matter via biochemical and physical pathways of litter mass loss. Nat Geosci 8:776776+. doi:10.1038/ngeo2520

10. Cotrufo MF, Wallenstein MD, Boot CM, Denef K, Paul E (2013) The Microbial Efficiency-Matrix Stabilization (MEMS) framework integrates plant litter decomposition with soil organic matter stabilization: do labile plant inputs form stable soil organic matter? Glob Chang Biol 19:988-995. doi:10.1111/gcb. 12113

11. Dai LM, Chen G, Deng HB, Ji LZ, Hao ZQ, Wang QL (2004) Structure characteristics and health distance assessment of various disturbed communities of Korean pine and broadleaved mixed forest in Changbai Mountains Chinese Journal of Applied Ecology:1750-1754

12. Dawud SM et al (2017) Tree species functional group is a more important driver of soil properties than tree species diversity across major European. forest types Functional Ecology 31:1153-1162. doi:10.1111/1365-2435.12821

13. de Avila AL et al (2018) Disturbance intensity is a stronger driver of biomass recovery than remaining tree-community attributes in a managed Amazonian forest. J Appl Ecol 55:1647-1657. doi:10.1111/1365-2664.13134

14. Edwards DP, Tobias JA, Sheil D, Meijaard E, Laurance WF (2014) Maintaining ecosystem function and services in logged tropical forests. Trends Ecol Evol 29:511-520. doi:10.1016/j.tree.2014.07.003

15. Fang WD, Kang XG, Zhao HY, Huang XF, Gong ZW, Gao Y, Feng QX (2011) Soil characteristics and water conservation of different forest types in Changbai Mountain. Journal of Beijing Forestry University 33:40-47

16. Finegan B et al (2015) Does functional trait diversity predict above-ground biomass and productivity of tropical forests? Testing three alternative hypotheses. J Ecol 103:191-201. doi:10.1111/1365- 
2745.12346

17. Fischer $C$ et al (2019) Plant species richness and functional groups have different effects on soil water content in a decade-long grassland experiment. J Ecol 107:127-141. doi:10.1111/13652745.13046

18. Fischer $C$ et al (2015) Plant species diversity affects infiltration capacity in an experimental grassland through changes in soil properties. Plant Soil 397:1-16. doi:10.1007/s11104-014-2373-5

19. Grace JB et al (2016) Integrative modelling reveals mechanisms linking productivity and plant species. richness Nature 529:390-390+. doi:10.1038/nature16524

20. Grime JP (1998) Benefits of plant diversity to ecosystems: immediate, filter and founder effects. J Ecol 86:902-910. doi:10.1046/j.1365-2745.1998.00306.x

21. Hao ZQ, Guo SL, Ye J (2003) Canonical correspondence analysion of woody plants with their environments on the northern slope of Changbai mountain Acta Phytoecologica Sinica:733-741

22. Hao ZQ, Wang LH (1998) Water conservaion capacities of soils with major forest types in mountainous regions of east Liaoning Province Chinese Journal of Applied Ecology:3-5

23. Hao ZQ, Zhang J, Song B, Ye J, Li BH (2007) Vertical structure and spatial associations of dominant tree species in an old-growth temperate forest. For Ecol Manage 252:1-11. doi:10.1016/j.foreco.2007.06.026

24. Harms KE, Condit R, Hubbell SP, Foster RB (2001) Habitat associations of trees and shrubs in a 50-ha neotropical forest plot. J Ecol 89:947-959. doi:10.1046/j.0022-0477.2001.00615.x

25. Hoyle RH (2012) Handbook of structural equation modeling. Guilford Press, New York

26. Jiao F, Wen Z-M, An S-S (2011) Changes in soil properties across a chronosequence of vegetation restoration on the Loess. Plateau of China Catena 86:110-116. doi:10.1016/j.catena.2011.03.001

27. Jucker T et al (2018) Topography shapes the structure, composition and function of tropical forest landscapes. Ecol Lett 21:989-1000. doi:10.1111/ele.12964

28. Kahl T, Bauhus J (2014) An index of forest management intensity based on assessment of harvested tree volume, tree species composition and dead wood origin Nature Conservation 7 doi:10.3897/natureconservation.7.7281

29. Kammer PM, Schöb C, Eberhard G, Gallina R, Meyer R, Tschanz C (2013) The relationship between soil water storage capacity and plant species diversity in high alpine vegetation. Plant Ecology Diversity 6:457-466. doi:10.1080/17550874.2013.783142

30. Laliberté $E$, Legendre P (2010) A distance-based framework for measuring functional diversity from multiple. traits Ecology 91:299-305

31. Lange M, Koller-France E, Hildebrandt A, Oelmann Y, Wilcke W, Gleixner G (2019) How plant diversity impacts the coupled water, nutrient and carbon cycles. In: Eisenhauer N, Bohan DA, Dumbrell AJ (eds) Mechanisms Underlying the Relationship between Biodiversity and Ecosystem Function, vol 61. Advances in Ecological Research. pp 185-219. doi:10.1016/bs.aecr.2019.06.005 
32. Lin D, Anderson-Teixeira KJ, Lai J, Mi X, Ren H, Ma K (2016) Traits of dominant tree species predict local scale variation in forest aboveground and topsoil carbon stocks. Plant Soil 409:435-446. doi:10.1007/s11104-016-2976-0

33. Liu X, Zhang G, Heathman GC, Wang Y, Huang C-h (2009) Fractal features of soil particle-size distribution as affected by plant communities in the forested region of Mountain Yimeng. China Geoderma 154:123-130. doi:10.1016/j.geoderma.2009.10.005

34. Liu Y, Miao HT, Chang XF, Wu GL (2019) Higher species diversity improves soil water infiltration capacity by increasing soil organic matter content in semiarid grasslands. Land Degradation Development 30:1599-1606. doi:10.1002/Idr.3349

35. Loreau M, Hector A (2001) Partitioning selection and complementarity in biodiversity experiments. Nature 412:72-76. doi:10.1038/35083573

36. Lu R (1999) Analytical methods of soil and agricultural chemistry China Agricultural Science and Technology Press, Beijing:107-240

37. Lü YH, Hu J, Sun FX, Zhang LW (2015) Water retention and hydrological regulation: harmony but not the same in terrestrial hydrological ecosystem services. Acta Ecol Sin 35:5191-5196

38. Millar Cl, Stephenson NL (2015) Temperate forest health in an era of emerging megadisturbance. Science 349:823-826. doi:10.1126/science.aaa9933

39. Mo F, Li XY, He SX, Wang XX (2011) Evaluation of soil and water conservation capacity of different forest types in Dongling Mountain. Acta Ecol Sin 31:5009-5016

40. Rabot E, Wiesmeier M, Schlueter S, Vogel HJ (2018) Soil structure as an indicator of soil functions. A review Geoderma 314:122-137. doi:10.1016/j.geoderma.2017.11.009

41. Rawls WJ, Pachepsky YA, Ritchie JC, Sobecki TM, Bloodworth H (2003) Effect of soil organic carbon on soil. water retention Geoderma 116:61-76. doi:10.1016/s0016-7061(03)00094-6

42. Reich PB, Sendall KM, Stefanski A, Rich RL, Hobbie SE, Montgomery RA (2018) Effects of climate warming on photosynthesis in boreal tree species depend on. soil moisture Nature 562:263-263+. doi:10.1038/s41586-018-0582-4

43. Rosseel Y (2012) lavaan: An R Package for Structural Equation Modeling. J Stat Softw 48:1-36. doi:10.18637/jss.v048.i02

44. Seidl R, Spies TA, Peterson DL, Stephens SL, Hicke JA (2016) Searching for resilience: addressing the impacts of changing disturbance regimes on forest ecosystem services. J Appl Ecol 53:120-129. doi:10.1111/1365-2664.12511

45. Shao GF, Schall P, Weishampel JF (1994) Dynamic simulations of mixed broadleaved-Pinus koraiensis forests in the Changbaishan biosphere reserve of China. For Ecol Manage 70:169-181. doi:10.1016/0378-1127(94)90084-1

46. Song HJ et al (2014) Woody plant species composition and community structure in residual fragments of broadleaved Korean pine mixed forests in Changbai Mountains area Chinese. J Appl Ecol 25:1239-1249 
47. Teixeira LH, Oliveira BF, Krah F-S, Kollmann J, Ganade G (2020) Linking plant traits to multiple soil functions in semi-arid ecosystems J Arid Environ 172 doi:10.1016/j.jaridenv.2019.104040

48. Thom D, Seidl R (2016) Natural disturbance impacts on ecosystem services and biodiversity in temperate and boreal forests. Biol Rev 91:760-781. doi:10.1111/brv.12193

49. Tilman D, Lehman CL, Thomson KT (1997) Plant diversity and ecosystem productivity: Theoretical considerations. Proc Natl Acad Sci U S A 94:1857-1861. doi:10.1073/pnas.94.5.1857

50. Trumbore S, Brando P, Hartmann H (2015) Forest health global change Science 349:814-818. doi:10.1126/science.aac6759

51. van der Plas F (2019) Biodiversity and ecosystem functioning in naturally assembled communities. Biol Rev 94:1220-1245. doi:10.1111/brv.12499

52. Villeger S, Mason NWH, Mouillot D (2008) New multidimensional functional diversity indices for a multifaceted framework in. functional ecology Ecology 89:2290-2301. doi:10.1890/07-1206.1

53. Wang C, Zhao CY, Xu ZL, Wang Y, Peng HH (2013) Effect of vegetation on soil water retention and storage in a semi-arid alpine forest catchment. Journal of Arid Land 5:207-219. doi:10.1007/s40333-013-0151-5

54. Wang QK, Wang SL (2005) Forming and Stable Mechanism of Soil Aggregate and Influencing Factors Chinese. J Soil Sci 36:415-421. doi:10.19336/j.cnki

55. Wen Z, Zheng H, Smith JR, Ouyang Z (2021) Plant functional diversity mediates indirect effects of land-use intensity on soil water conservation in the dry season of tropical areas. For Ecol Manage 480:118646. doi:10.1016/j.foreco.2020.118646

56. Wen Z, Zheng H, Smith JR, Zhao H, Liu L, Ouyang Z (2019) Functional diversity overrides communityweighted mean traits in linking land-use intensity to hydrological ecosystem services. Sci Total Environ 682:583-590. doi:10.1016/j.scitotenv.2019.05.160

57. Wösten JHM, Pachepsky YA, Rawls WJ (2001) Pedotransfer functions: bridging the gap between available basic soil data and missing soil hydraulic characteristics. J Hydrol 251:123-150. doi:10.1016/s0022-1694(01)00464-4

58. Wu G-L, Zhang Z-N, Wang D, Shi Z-H, Zhu Y-J (2014) Interactions of soil water content heterogeneity and species diversity patterns in semi-arid steppes on the Loess Plateau of China. J Hydrol 519:1362-1367. doi:10.1016/j.jhydrol.2014.09.012

59. Wu GL, Yang Z, Cui Z, Liu Y, Fang NF, Shi ZH (2016) Mixed artificial grasslands with more roots improved mine soil infiltration capacity. J Hydrol 535:54-60. doi:10.1016/j.jhydrol.2016.01.059

60. Xia JB, Zhao ZG, Fang Y (2017) Soil hydro-physical characteristics and water retention function of typical shrubbery stands. in the Yellow River Delta of China Catena 156:315-324. doi:10.1016/j.catena.2017.04.022

61. Xu Y, Zhang Y, Yang J, Lu Z (2020) Influence of tree functional diversity and stand environment on fine root biomass and necromass in four types of evergreen broad-leaved forests Global. Ecology Conservation 21:e00832. doi:10.1016/j.gecco.2019.e00832 
62. Yang F et al (2014) Organic matter controls of soil water retention in an alpine grassland and its significance for hydrological processes. J Hydrol 519:3086-3093. doi:10.1016/j.jhydrol.2014.10.054

63. Yuan Z et al (2019) Multiple abiotic and biotic pathways shape biomass demographic processes in temperate forests Ecology:e02650-e02650 doi:10.1002/ecy.2650

64. Yuan $\mathrm{Z}$ et al (2018) Aboveground carbon storage is driven by functional trait composition and stand structural attributes rather than biodiversity in temperate mixed forests recovering from disturbances. Ann For Sci 75:2-13. doi:10.1007/s13595-018-0745-3

65. Yuan Z et al (2016) Multiple metrics of diversity have different effects on temperate forest functioning. over succession Oecologia 182:1175-1185. doi:10.1007/s00442-016-3737-8

66. Zhang BA, Li WH, Xie GD, Xiao Y (2010) Water conservation of forest ecosystem in Beijing and its value. Ecol Econ 69:1416-1426. doi:10.1016/j.ecolecon.2008.09.004

67. Zhang WG, An SQ, Xu Z, Cui J, Xu Q (2011) The impact of vegetation and soil on runoff regulation in headwater streams on the east Qinghai-Tibet Plateau. China Catena 87:182-189. doi:10.1016/j.catena.2011.05.020

68. Zhang X, Zhao W, Wang L, Liu Y, Liu Y, Feng Q (2019) Relationship between soil water content and soil particle size on typical slopes of the Loess Plateau during a drought year. Sci Total Environ 648:943-954. doi:10.1016/j.scitotenv.2018.08.211

69. Zhang YW, Deng L, Yan WM, Shangguan ZP (2016) Interaction of soil water storage dynamics and long-term natural vegetation succession on the Loess Plateau. China Catena 137:52-60. doi:10.1016/j.catena.2015.08.016

70. Zhou $\mathrm{G}$ et al (2019) Climate and litter $\mathrm{C} / \mathrm{N}$ ratio constrain soil organic carbon accumulation. National Science Review 6:746-757. doi:10.1093/nsr/nwz045

\section{Figures}




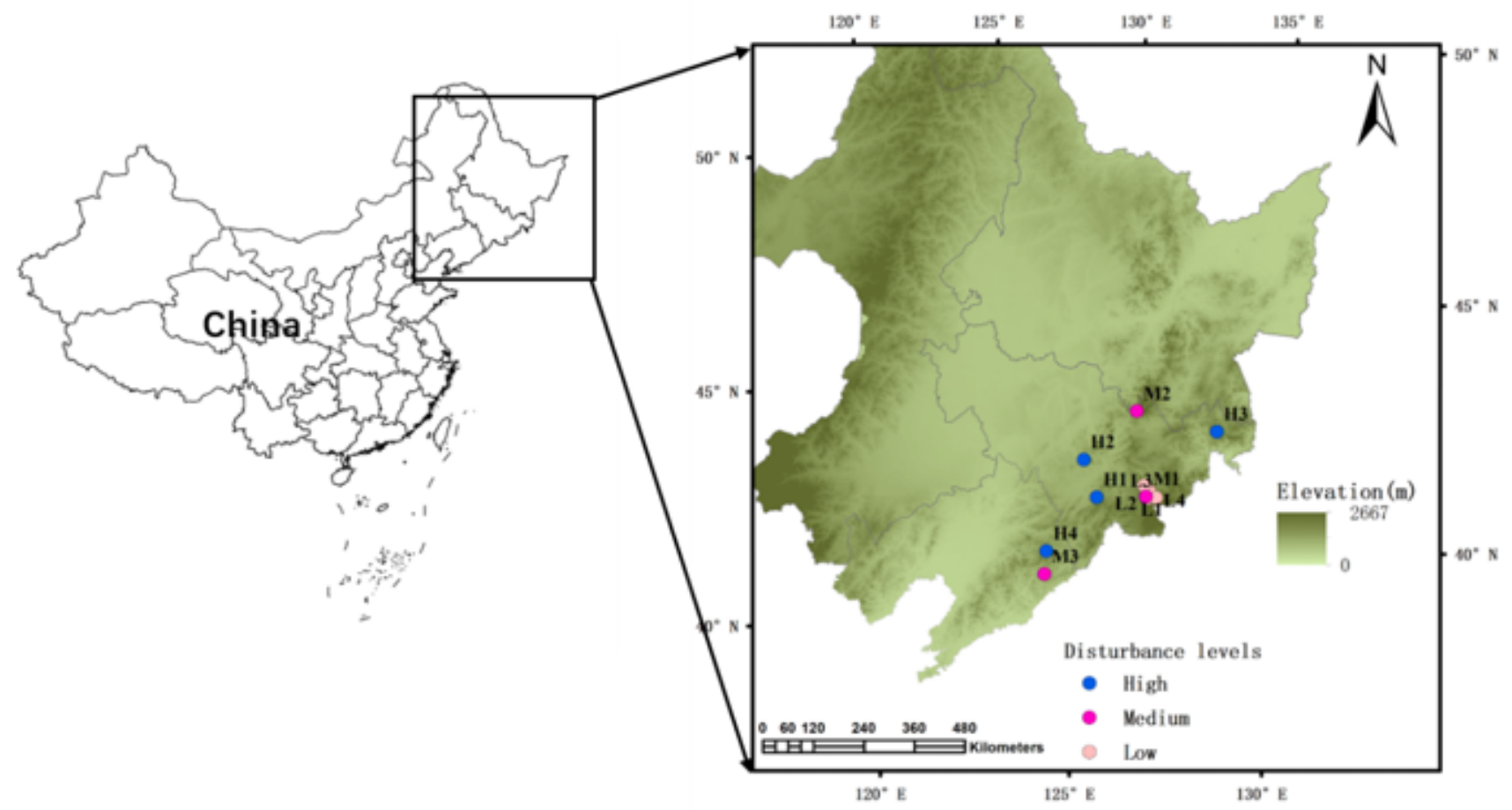

Figure 1

Map of China showing the study area and distribution of 11 permanent forest sites. Color represents disturbance level at each site. Note: The designations employed and the presentation of the material on this map do not imply the expression of any opinion whatsoever on the part of Research Square concerning the legal status of any country, territory, city or area or of its authorities, or concerning the delimitation of its frontiers or boundaries. This map has been provided by the authors.
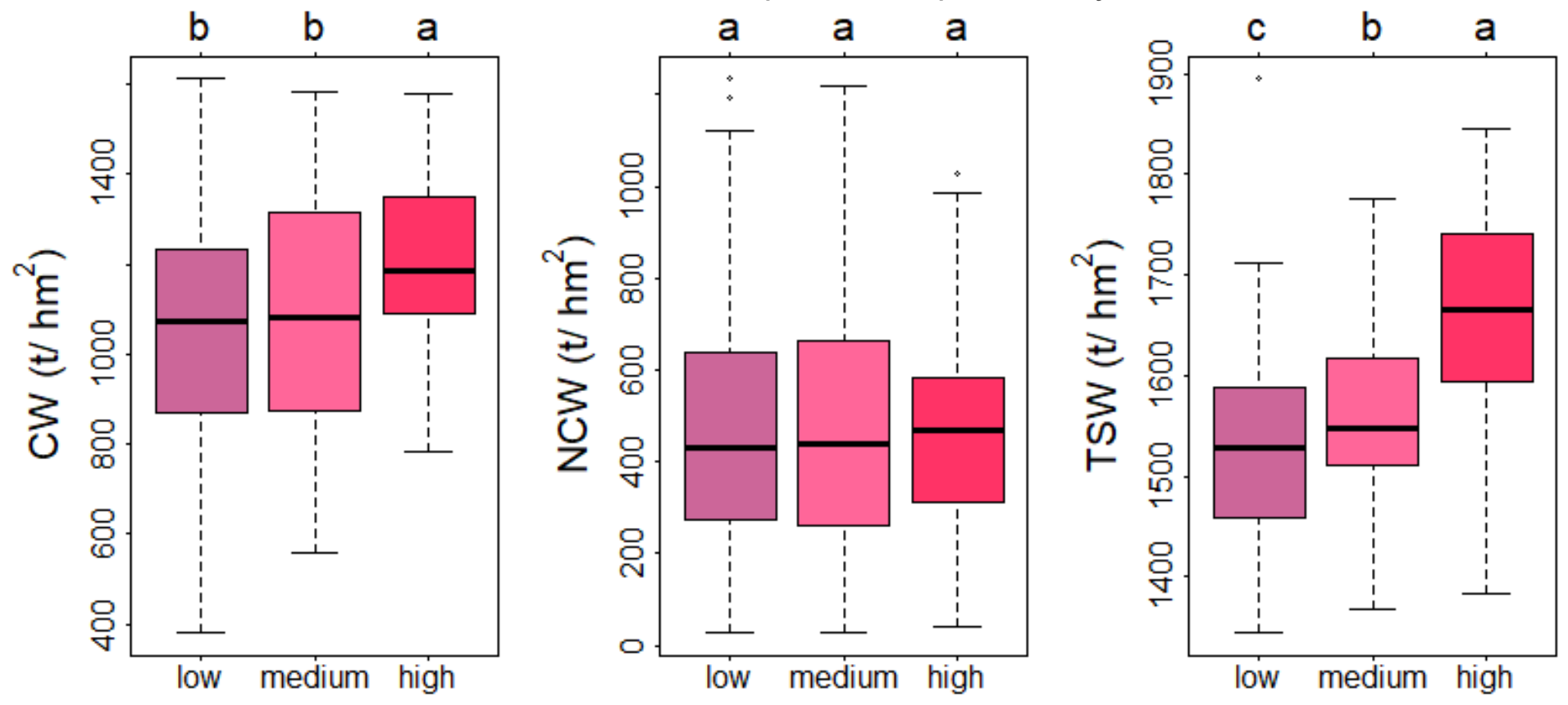

Disturbance level 
Figure 2

Boxplots showing the differences for soil water storage capacity among disturbance intensity levels. Boxes having different letters are showing significant differences at $\mathrm{P}<0.05$ (Tukey's test). Factors are soil capillary water storage content $(\mathrm{CW})$, soil non-capillary water storage content $(\mathrm{NCW})$, soil saturated water storage content (TSW).

a) Soil capillary water storage content (CW) model

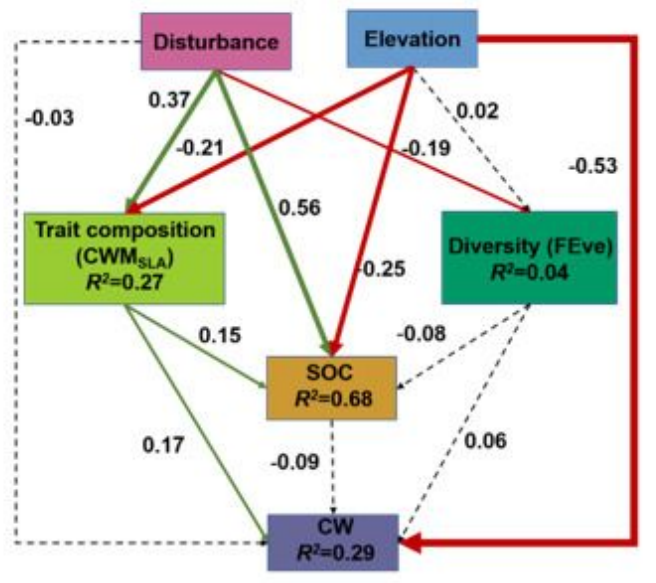

b) Soil non-capillary water storage content (NCW) model

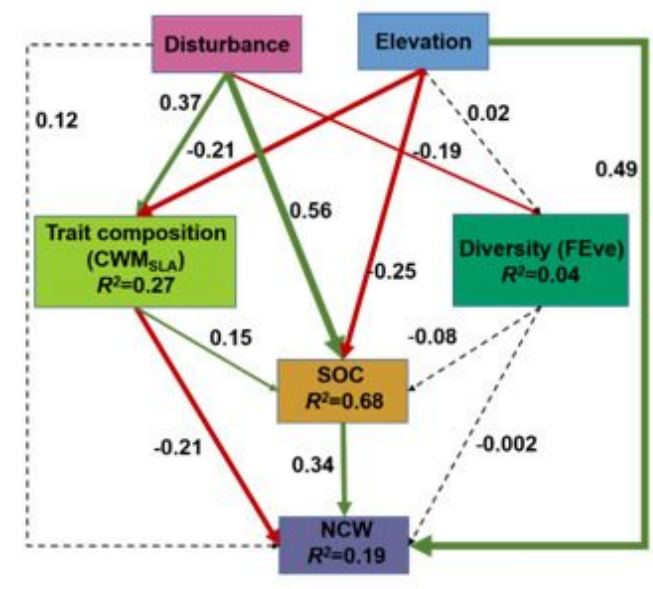

c) Soil total water storage content (TSW) model

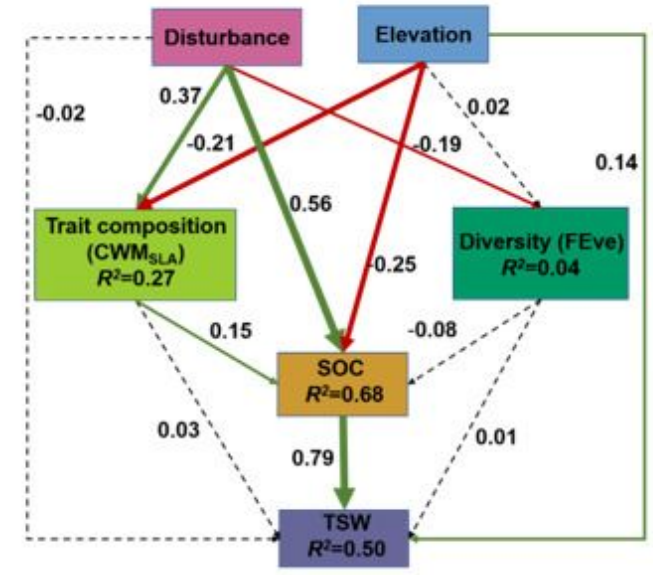

Figure 3 
Best-fitted structural equation models for linking disturbance, elevation, functional trait composition, functional trait diversity, SOC and soil water storage capacity, i.e. (a) CW, (b) NCW, and (c) TSW. Solid and dashed arrows represent significant ( $\mathrm{p} \otimes 0.05$ ) and non-significant effects. For all paths, standardized regression coefficients are given. Model fit statistics: a) $\mathrm{CFI}=1.00, \mathrm{SRMR}=0.01$, Chi-square $=1.61(\mathrm{P}=$ $0.2)$, and $\mathrm{AIC}=2537.03 ; \mathrm{b}) \mathrm{CFI}=1.00, \mathrm{SRMR}=0.01$, Chi-square $=1.61(\mathrm{P}=0.2)$, and $\mathrm{AIC}=2944.87 ; \mathrm{c}) \mathrm{CFI}$ $=1.00$, SRMR $=0.01$, Chi-square $=1.61(P=0.2)$, and $\mathrm{AIC}=1910.41$.

(a) Relative contribution (\%)

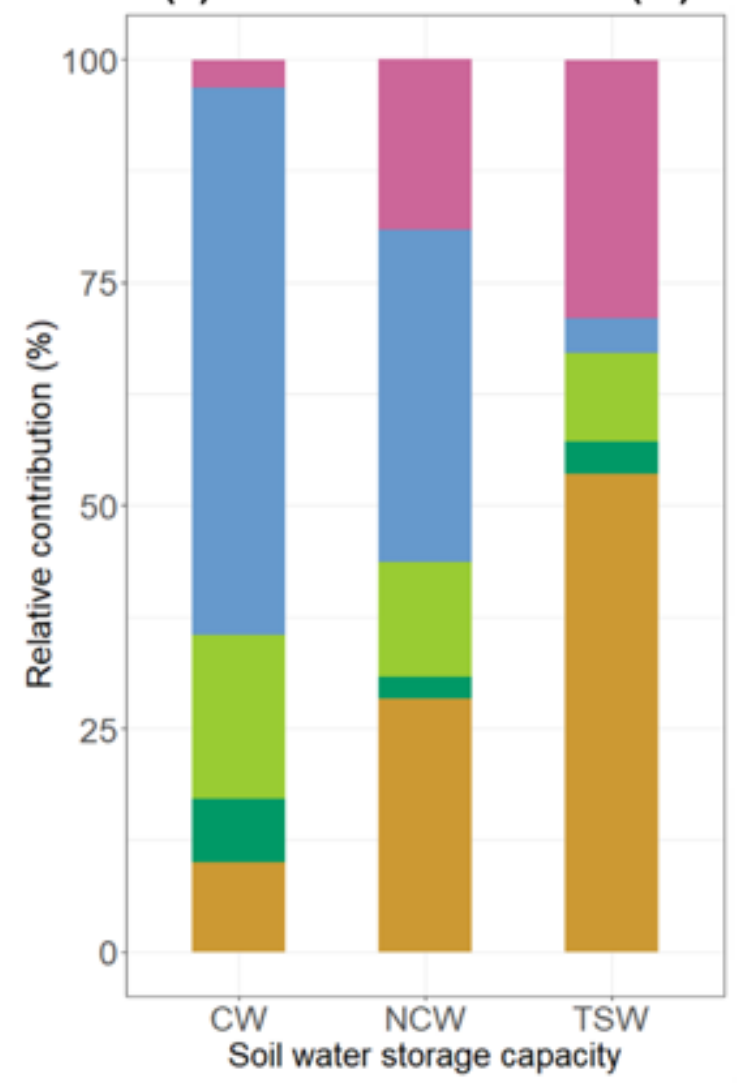

(b) Direct and indirect effects
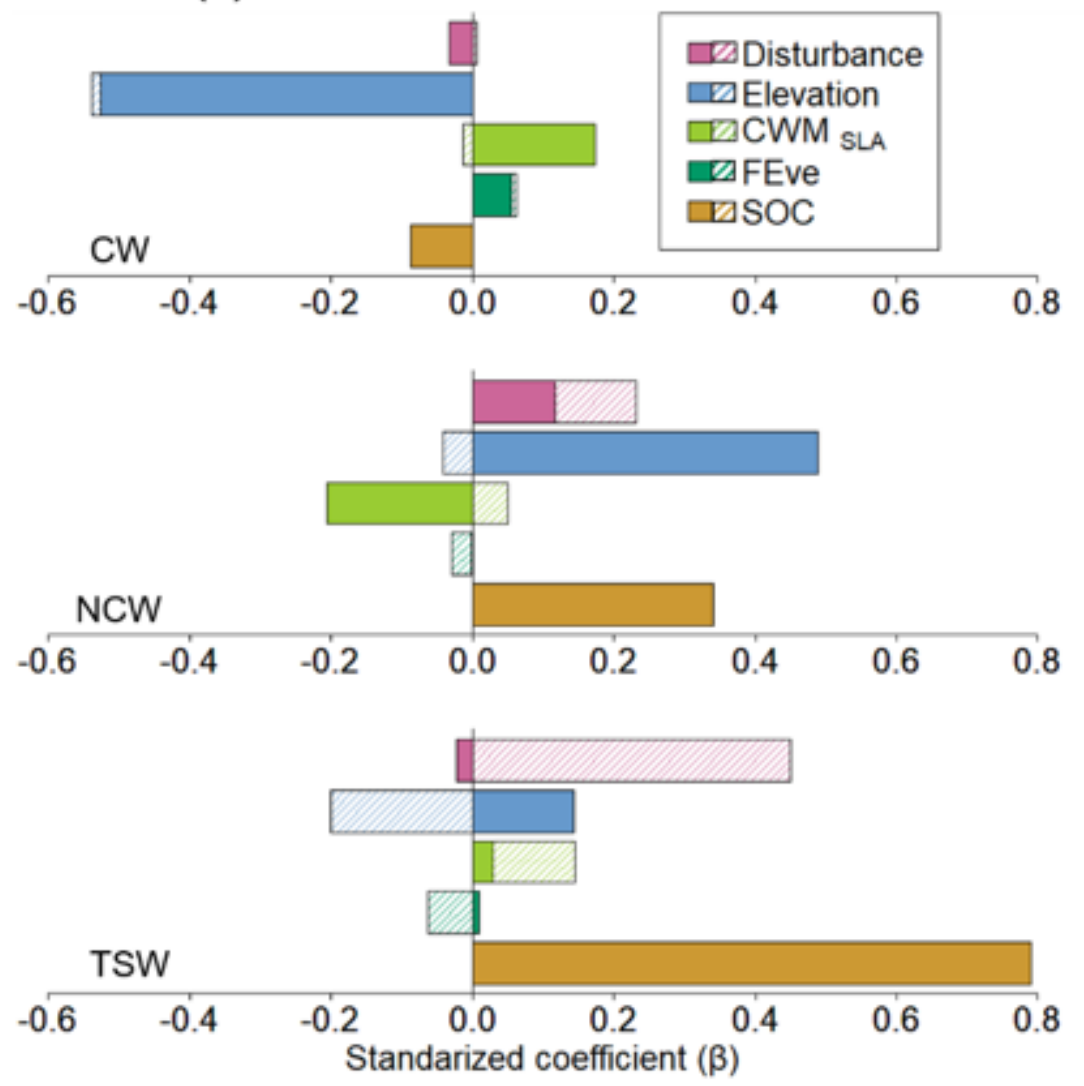

\section{Figure 4}

Relative contribution of each predictors (a), and its direct and indirect effects (b) on soil water storage capacity based on best-fitted SEMs. The solid color filled bar plots (b) shows direct effect whereas the pattern color filled bar shows indirect effect.

\section{Supplementary Files}

This is a list of supplementary files associated with this preprint. Click to download.

- Thesupportingtables.xlsx

- Thesupportingtext.docx 